\title{
Parotiditis crónica recurrente infantil: una revisión actualizada de la literatura
}

\author{
Recurrent chronic parotiditis in childhood: An update of the literature \\ Francisca Donoso-Hofer, ${ }^{\mathrm{a}, \mathrm{b}}$, Rodrigo Gutiérrez Díaz ${ }^{\mathrm{c}}$, Rodrigo Ortiz Cárdenas ${ }^{\mathrm{c}}$, \\ Gustavo Osorio Herrera ${ }^{c}$, Mirtha Landaeta Mendoza ${ }^{a}$
}

\author{
aDepartamento de Cirugía Máxilofacial Facultad de Odontología, Universidad de Chile. Santiago, Chile \\ bServicio de Cirugía Máxilofacial Hospital San Juan de Dios. Santiago, Chile. \\ 'Facultad de Odontología, Universidad de Chile. Santiago, Chile
}

Recibido el 29 de marzo de 2017; aceptado el 1 de julio de 2017

\begin{abstract}
Resumen
Introducción: La parotiditis crónica recurrente infantil (PCRI) es una patología relevante. Su diagnóstico es principalmente clínico, pero se apoya en exámenes imagenológicos. El enfoque actual del tratamiento es diverso. El objetivo es realizar una revisión actualizada sobre las características clínicas, exámenes complementarios, modelos etiopatogénicos y protocolos terapéuticos. Material y Método: Se realizó una búsqueda bibliográfica en PUBMED utilizando los términos libres y términos MESH: PCRI, parotiditis recurrente, parotiditis crónica y parotiditis. Los filtros utilizados fueron pacientes humanos, hasta 18 años, con resumen. En el buscador Scielo se incluyeron los términos libes Parotiditis y crónica. Se incluyeron artículos publicados en idiomas inglés, español o portugués hasta el año 2017. Resultados: En el buscador PUBMED se encontraron 119 artículos de los cuales sólo se incluyeron 44. La exclusión de los artículos restantes se debió a idioma, acceso al artículo o ausencia de relación entre el artículo y la revisión propuesta. En el buscador Scielo se encontraron 6 artículos de los cuales 5 fueron seleccionados. La evaluación multidisciplinaria permite el tratamiento oportuno. Su diagnóstico es clínico pero se apoya en exámenes imagenológicos, como la ecografía y la sialografía. Conclusiones: El enfoque actual de tratamiento es conservador, y la mejor evidencia disponible apoya el uso de sialendoscopia con irrigación y administración de antibióticos y/o corticoides vía conducto parotídeo, sin embargo, existirían buenos resultados con lavados intraglandulares con soluciones fisiológicas sin necesidad de sialendoscopio.
\end{abstract}

Palabras clave:

Parotiditis recurrente infantil, glándulas parótidas 


\section{Abstract}

Introduction: Recurrent childhood chronic parotiditis (RCCP) is a relevant pathology. Its diagnosis is mainly clinical, but it relies on imaging tests. The current treatment approach is diverse. The aim of this article is to update the clinical features, complementary tests, etiopathogenic models and therapeutic protocols of this disease. Material and Method: A bibliographic search was performed in PUBMED using the free terms and MESH terms: RCCP, recurrent parotiditis, chronic parotiditis and parotiditis. The filters used were human patients, up to 18 years old, with abstract. In SCIELO the free terms included were Parotiditis and chronic. Articles published in English, Spanish or Portuguese until 2017 were included. Results: In PUBMED 119 articles were found and 44 were included. The exclusion of the remaining articles was due to language, access to the article or absence of relationship between the article and the proposed revision. In SCIELO 6 articles were found 6 of which 5 were selected. The multidisciplinary asses of patients with RCCP is considered the appropriate treatment. Its diagnosis is clinical but it relies on imaging tests, such as echography and sialography. Conclusions: The current treatment approach is conservative, and the best available evidence supports the use of sialendoscopy with irrigation and administration of antibiotics and/or corticosteroids via the parotid duct. However, there would be proper results with intraglandular lavage with physiological solutions without the need for a sialendoscope.

\section{Keywords:}

Recurrent childhood parotiditis, parotid glands

\section{Introducción}

Aún existen patologías con etiopatogenia desconocida en donde se aplican tratamientos basados en un modelo etiopatogénico, sintomático o en la experiencia clínica. La parotiditis crónica recurrente infantil (PCRI) se enmarca en este contexto. La parotidomegalia es una de sus características clínicas más conservadas, y es común a otras patologías de la glándula parótida y manifestaciones de enfermedades sistémicas, por lo que el diagnóstico diferencial es mandatorio. El objetivo de este trabajo es realizar una revisión bibliográfica actualizada sobre las características clínicas más importantes de PCRI, exámenes complementarios para el diagnóstico y exponer modelos etiopatogénicos y protocolos terapéuticos, haciendo hincapié en la mirada que el odontólogo tiene de esta patología.

Se realizó una búsqueda bibliográfica en PUBMED utilizando los términos libres y términos MESH: PCRI, parotiditis recurrente, parotiditis crónica y parotiditis. Los filtros utilizados fueron pacientes humanos, hasta 18 años y artículos con resumen. En el buscador Scielo se incluyeron los términos libres Parotiditis y crónica. En ambos buscadores se incluyeron artículos publicados en idiomas inglés, español o portugués hasta el año 2017. En el buscador PUBMED se encontraron 119 artículos de los cuales sólo se incluyeron 44. La exclusión de los artículos restantes se debió a idioma, acceso al artículo o ausencia de relación entre el artículo y la revisión propuesta. En el buscador Scielo se encontraron 6 artículos de los cuales 5 fueron seleccionados. El articulo restante no se incluyó por no tener relación con la revisión propuesta.
Los artículos seleccionados correspondían a revisiones bibliográficas, estudios clínicos, revisiones sistemáticas y casos clínicos. Los hallazgos mas relevantes se presentan a continuación.

\section{Definición y epidemiología}

La PCRI es una enfermedad benigna de las glándulas parótidas y la segunda patología más común de glándulas salivales en niños, después de la parotiditis viral $^{1-8}$. Su prevalencia es desconocida ${ }^{2,8}$. Cursa con episodios recurrentes de inflamación parotídea, asociados a sialectasia no obstructiva $a^{1-5,9-15}$, con períodos de remisión de semanas o meses, donde existe ausencia de sintomatología glandular ${ }^{4,18,19}$.

Se presenta en un amplio rango de edad, que va desde los 3 meses $^{7,11}$ hasta los 16 años ${ }^{1,2,7,10,11,13}$. El inicio de los signos y síntomas, se muestra una distribución bimodal: entre los 3-6 años ${ }^{1-4,7,11,13,16-18}$, y otro a los 10 años $^{5,8}$. Respecto a la distribución por sexo, se relata mayor frecuencia en hombres ${ }^{1,2,8,19-23}$ Generalmente se resuelve en la pubertad ${ }^{3}$, no obstante, en un 10-20\% de los $\operatorname{casos}^{10}$, puede recurrir posteriormente ${ }^{17}$. Dos mecanismos explicarían la resolución de los síntomas: atrofia total ${ }^{1} \mathrm{o}$ regeneración de la glándula desde células ductales sobrevivientes ${ }^{11,13}$.

\section{Etiología}

El enfoque actual la considera una patología multifactorial y considera factores como enfermedades respiratorias, anomalías anatómicas, alteraciones inmuno- 
lógicas, factores genéticos, alteraciones oclusales y obstrucción del conducto parotídeo ${ }^{1,2,4,5,7,8,10,11,13-17,24,26,30-32}$; la literatura publicada hasta la fecha ofrece estudios más contundentes de factores etiológicos a las enfermedades respiratorias y malformaciones anatómicas que se describen a continuación:

\section{Enfermedades respiratorias}

Infecciones del tracto respiratorio superior (ITRS) tendrían un rol, sobre todo, en pacientes que cursan con deshidratación ${ }^{1,5,10,11,14,16}$. La deshidratación generada por una ITRS produce una disminución del flujo salival parotídeo, creando un ambiente ideal para la infección bacteriana ${ }^{11}$. Esta condición sólo afectaría a las glándulas parótidas ya que las glándulas submandibulares no se ven afectadas dado su mayor flujo salival ${ }^{27}$.

En Chile, Landaeta et al, reportó que 49 de 50 niños con PCRI presentaban antecedentes de enfermedades respiratorias (amigdalitis o bronquitis) u otitis, y propone que bacterias de la microbiota respiratoria penetrarían a través del conducto parotídeo. La colonización de estas bacterias provocaría un cambio metaplásico en la glándula, predominando una saliva más mucosa y densa ${ }^{14}$.

\section{Anomalías anatómicas}

Existen anomalías anatómicas que alterarían la capacidad de excreción de la glándula ${ }^{1,3,7,11,25}$. Nahlieli et al y Quenin et al, de forma independiente y mediante sialendoscopia concluyen que la PCRI es resultado de una malformación del conducto parotídeo ${ }^{1,7}$. Ambos describen una apariencia blanquecina de su lumen, por alteración en la angiogénesis normal, además de estenosis $^{1,7}$. Existiría deterioro en el esfínter del conducto, afectando su capacidad de lavado, obstruyéndose por precipitación de tapones mucosos y favoreciendo una infección ascendente desde la cavidad oral, dando inicio a un cuadro acompañado de dolor, fiebre y supuración ${ }^{1,28}$.

Por otra parte, Leerdam et al proponen 2 mecanismos. La estasis producida por disminución del flujo salival generaría daño en los ductos, y existiría una anomalía anatómica que predispondría a la inflamación o bien a una infección leve, explicando la imagen sialográfica bilateral de sialectasis ${ }^{5,33}$, aun cuando los síntomas fueran unilaterales ${ }^{5}$.

\section{Características clínicas}

La PCRI presenta episodios agudos de dolor, aumento de volumen, eritema local, induración parotídea y dificultades en la masticación. Usualmente los pacientes presentan fiebre y malestar general. Puede presentarse unilateral o bilateralmente $\mathrm{e}^{1,3-5,7,8,12,15-17,24}$. La duración de los episodios fluctúa entre 0.5 y 14 días ${ }^{16,25}$. El número de episodios por año es variable ${ }^{3,7}$, con un promedio de 3 o 4 anuales ${ }^{3,5,11,13}$, reportándose incluso 30 recurrencias en un $a \tilde{n} o^{2}$. Posterior a los episodios, la patología progresa a una fase crónica asintomática ${ }^{4}$.

$\mathrm{Al}$ examen clínico del conducto parotídeo se observa un exudado descrito como: mucoso ${ }^{14,15}$, purulento $^{3,12-15,25,26}$, globoso $^{14}$, mucopurulento ${ }^{2,10}$, blanquecino y granulado ${ }^{15,19,21}$ (figura 1). Signos patognomónicos -perceptibles al examen con lupas- son la dilatación de la entrada del conducto, placas amarillentas en la saliva parotídea y una masa firme a la palpación en la glándula sintomática ${ }^{1}$.

Morales-Bozo et al estudiaron alteraciones en la saliva parotídea. Mediante espectofotometría evidenció niveles elevados de proteínas en comparación con pacientes control ${ }^{15}$.

Esto podría deberse a una producción aumentada, filtración desde el plasma o disminución en el contenido de agua ${ }^{15,16}$. Además, una fracción de las proteínas salivales se organizaba en complejos supramoleculares que podría explicar el enlentecimiento del flujo sali$\mathrm{val}^{15}$.

\section{Diagnóstico y exámenes complementarios}

El diagnóstico es clínico y se complementa con imágenes ${ }^{4,5,8,17}$. El criterio clínico considera 2 episodios de recurrencia de sialoadenitis antes de la pubertad ${ }^{2}$, cuya severidad está determinada por la frecuencia de los episodios ${ }^{7,26}$. La sialectasia puede demostrarse a través de distintos exámenes imagenológicos como la sialografía y ecografía que se utilizan ampliamente en

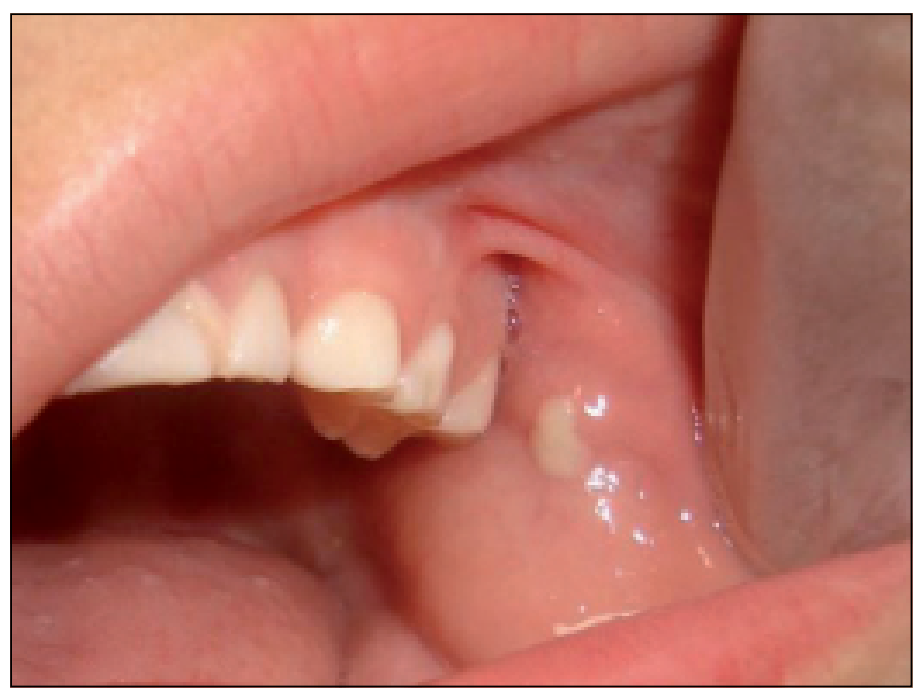

Figura 1. Exudado purulento localizado en la salida del conducto de Stennon o parotideo. 
Figura 2. Sialografía de paciente con PCR. Se observa normalidad del conducto parotídeo del lado derecho (A) mientras que en el lado izquierdo se observa la imagen de ciruelo en flor que revela la sialectasia (B).
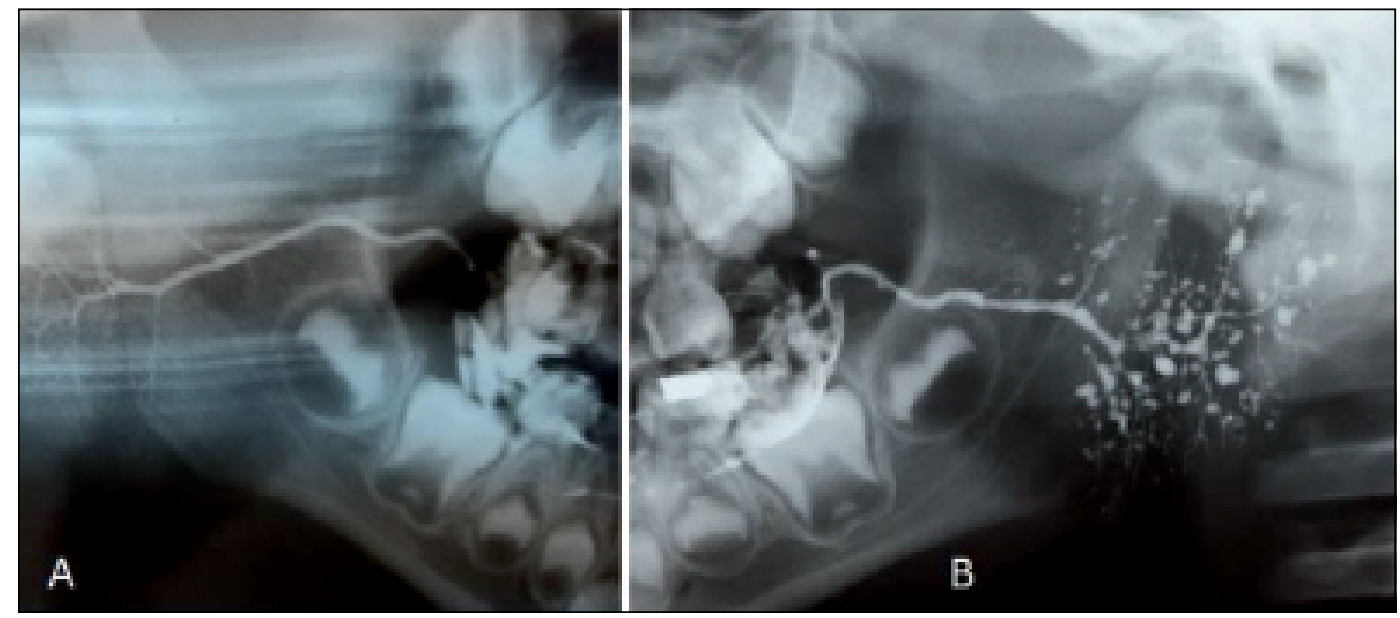

el sistema hospitalario o también, a través de exámenes cuyo acceso es más restringido como la sialendoscopia, resonancia nuclear magnética y sialografía con resonancia nuclear magnética.

La sialografía se define como una radiografía panorámica con inyección de medio de contraste para observar el sistema ductal y acinar de las glándulas parótidas. En PCRI se visualiza una combinación de sialectasia, constricciones, torceduras, y dilataciones. En el 73\% de los casos la imagen es bilateral ${ }^{1}$ (figura 2).

Seifert, describe una sialectasia puntiforme, bilateral y conducto parotídeo con imagen normal, mientras que en adultos afectados, principalmente constricciones y dilataciones afectando uno de los conductos parotídeos ${ }^{19,34}$ Por lo general, se utiliza un medio de contraste yodado que se inyecta en el conducto parotídeo y de manera inmediata se realiza la radiografía. La imagen característica es la de "ciruelo en flor" en



Figura 3. Ecografía parotídea en paciente con proceso agudo en donde se observan múltiples imágenes nodulares hipoecogénicas en el parénquima (A, flechas). En contraste, se observa la ecografia del lado sano em el mismo paciente (B). donde se observa la indemnidad del árbol excretor y la sialectasia (figura 2).

Dentro de las ventajas de este examen se puede mencionar su certeza diagnóstica, posibilidad de control en el tiempo ya que es una técnica estandarizada y, además, la inyección del medio de contraste contribuye al lavado glandular que es una de las bases del tratamiento. Como desventajas, se puede mencionar que se requiere de un radiólogo entrenado en la técnica y que está contraindicada cuando existen episodios de parotiditis con exudado purulento ${ }^{5}$.

En la ecografía se pesquisan múltiples áreas hipoecogénicas que se corresponderían con áreas de sialectasia. Sus ventajas incluyen: ausencia de radiación ionizante, de riesgo de alergia ya que no utiliza medio de contraste y la posibilidad de realizarla aún en presencia de infecciones y estenosis del conducto parotídeo ${ }^{2}$. $\mathrm{Su}$ desventaja es que es operador dependiente. Puede ser útil cuando el paciente está en período agudo de la inflamación, ya que esto contraindica la realización de sialografía. Aunque algunos trabajos consideran a la ecografía como el examen que pudiera reemplazar completamente a la sialografía, es sólo esta última técnica la que ofrece un diagnóstico más certero ${ }^{35}$.

En la etapa aguda, la ecografía muestra un aumento de volumen parotídeo difuso, con disminución en la ecogenicidad de la glándula y múltiples imágenes nodulares hipoecogénicas en el parénquima que pueden corresponder a sialectasias e infiltración linfocitaria (figura 3$)^{12}$. Estas imágenes nodulares pueden persistir incluso una vez resuelto el episodio agudo, presentando un aspecto un aspecto similar a la parotiditis crónica o a la parotiditis observada en niños con $\mathrm{VIH} /$ SIDA $^{12}$.

Existen otros exámenes imagenológicos cuyo uso está limitado ya sea por la comorbilidad que producen o por los altos costos económicos asociados como es la 
sialendoscopia, resonancia nuclear magnética y sialografía con resonancia nuclear magnética.

La sialendoscopia involucra la introducción de un endoscopio de generalmente $1,3 \mathrm{~mm}$ de diámetro a través del conducto parotídeo, bajo anestesia general. Se observa una coloración blanquecina al interior del conducto parotídeo, más notoria y extensa en el lado sintomático. Esto se produciría por una deficiencia en la vascularidad que recubre normalmente su lumen ${ }^{1}$.

Tanto la Resonancia nuclear magnética como la Sialografía con resonancia nuclear complementan la ecografía, evidenciando las fases de la inflamación. Durante la inflamación aguda, se visualiza una señal hipointensa en $\mathrm{T} 1$ e hiperintensa en $\mathrm{T} 2$, en tanto que en la inflamación crónica, se evidencia una señal isointensa tanto en $\mathrm{T} 1$ como en $\mathrm{T}^{4}$.

También complementa la evaluación del estado del parénquima y sistema ductal, sin necesidad de radiación ni medios de contraste, teniendo importancia al poder diferenciar la PCRI -en la cual se observa la unión entre los acinos dilatados con el sistema ductalde lesiones focales provenientes de patologías infiltrativas como el linfoma ${ }^{4}$.

La relación de la glándula con el nervio facial hace no recomendable el diagnóstico de la enfermedad mediante biopsia por la gran fibrosis perineural secundaria $^{3,5}$. A pesar de esto, algunos artículos describen las características histopatológicas de las glándulas con parotiditis crónica recurrente.

Estas características incluyen dilataciones pseudoquísticas de los ductos interlobulares ${ }^{1,11}$, infiltración linfocítica periductal ${ }^{1,3,5,11}$, fibrosis interacinar y algunos grados de atrofia y fibrosis de los acinos glandulares ${ }^{6,15}$. Se describen tres etapas en el desarrollo de la enfermedad.

Etapas iniciales muestran estructura arquitectónica lobular regular del parénquima glandular con ectasia del ducto, rodeados por pocos linfocitos y células plasmáticas.

Etapas avanzadas son caracterizadas por un incremento de la inflamación periductal y la apariencia de folículos linfáticos. Una transformación casi completa del parénquima con destrucción de las formaciones lobulares domina al término de la etapa "inmunológica". Estos datos apoyarían la hipótesis que las ectasias se deben al avance de la inflamación y no a malformaciones congénitas ${ }^{36}$.

\section{Diagnóstico diferencial}

Muchas patologías cursan con parotidomegalia y dolor en la zona, desde cuadros infecciosos locales (origen viral o bacteriano), patologías con componente inmunológico hasta neoplasias malignas.
El síndrome de Sjögren juvenil primario es muy infrecuente en la infancia y es comúnmente subdiagnosticado ${ }^{33,37}$. Su característica principal es la inflamación recurrente de las glándulas parótidas ${ }^{33}$ y por eso se le vincula a la Parotiditis recurrente. Puede presentarse junto a artralgias (más frecuente), artritis, xerostomía (más frecuente en adultos que en niños) ${ }^{28}$, xeroftalmia, queratoconjuntivitis seca, fenómeno de Raynaud y fotosensibilidad ${ }^{12,18,37}$.

Pocos niños con PCRI padecen Síndrome de Sjögren (SS) ${ }^{6,16}$, sin embargo, a mayor edad del comienzo de PCRI, más probable es que haya un diagnóstico subyacente de SS y deficiencia inmunológica ${ }^{5}$. Pruebas de laboratorio evidencian elevada velocidad de hemosedimentación, y valores positivos para anticuerpos extranucleares: anti-SS antígeno A (SSA/Ro), anti-SS antígeno B (SSB/La), anticuerpos antinucleares y factor reumatoide ${ }^{33}$.

Otra patología que cursa con inflamación de la parótida es la Parotiditis viral (paperas), causada por paramyxovirus. El paciente cursa con malestar general, fiebre, cefalea y escalofríos ${ }^{1}$. Produce inmunidad, por lo que no se esperan recurrencias ${ }^{28} \mathrm{y}$ ese hecho es suficiente para realizar el diagnóstico diferencial. Existe otro cuadro infeccioso que cursa con parotidomegalia que se denomina Parotiditis bacteriana aguda.

Esta se define como una inflamación de origen bacteriano causada frecuentemente por Staphylococcus aureus, Haemophilus influenzae y otras especies de estreptococos. Es bastante común en pacientes inmunocomprometidos, hospitalizados o en postoperatorio, siendo factores predisponentes la diabetes mellitus, falla renal, hipotiroidismo y el SS.

El compromiso es comúnmente unilateral y de evolución aguda. El conducto parotídeo podría excretar pus al masajear la glándula ${ }^{40}$.

En los pacientes con Virus de la inmunodeficiencia humana se define una patología denominada Parotiditis asociada a VIH. En estos pacientes se produce una parotidomegalia bilateral y asintomática. La saliva tiene aspecto normal, y hay compromiso moderado del estado general ${ }^{14}$. Hay múltiples causas, lesiones quísticas linfoepiteliales, linfoma no Hodgkin, infección bacteriana ${ }^{39,41}$, o bien síndrome de reconstitución inmune $^{34}$.

Existe una patología que es bastante infrecuente, pero que la clínica podría confundirse con una inflamación parotídea de tipo PCRI. La neumoparotiditis es una inflamación parotídea ocasionada por el ingreso patológico de aire a la glándula. Ocurre por un aumento en la presión combinado con anomalías anatómicas en el conducto, produciendo parotidomegalia y dolor. Pueden generarse infecciones secundarias que producen recurrencias ${ }^{38}$. La tomografía computada permite 
diagnosticarla, evidenciando la presencia patológica de aire dentro de la glándula, en espacio parafaríngeo e incluso en mediastino si es que ocurre una perforación de acinos parotídeos ${ }^{38}$.

\section{Relación con el síndrome de Sjögren}

Se ha postulado la posibilidad de que la PCRI sea precursora del SS, con xerostomía como síntoma principal y evidencia serológica de enfermedad autoinmune. Aparentemente un subconjunto de pacientes con PCRI estarían afectados por SS, por ende en ellos la PCRI no remitiría en la adultez 8 .

Sin embargo, la alta frecuencia de $\mathrm{PCRI}^{43}$ y la falta de criterios diagnósticos validados para SS juvenil ${ }^{37,43}$, hacen de ésta última una patología poco conocida y probablemente subdiagnosticada ${ }^{19}$.

Ambas entidades tienen algunas semejanzas: histológicamente, ambas exhiben infiltración linfocitaria que se inicia en la zona periductal y acaba presentando reducción significativa del parénquima glandular (más intenso en SS que en PCRI); imagenológicamente, ambas muestran durante la ultrasonografía, múltiples áreas con ecogenicidad heterogénea; no obstante, en la sialografía, el aspecto de "ciruelo en flor" (punteado o globular) aparece sólo en PCRI y no en SS (en la población infantil $)^{18}$.

En niños, la manifestación inicial de SS sería la parotiditis recurrente, y con el transcurso de los años se desarrollarían la xeroftalmia y xerostomía característica del SS en adultos ${ }^{43}$. La xeroftalmia se manifiesta como prurito, sensación de cuerpo extraño, signos de disminución del lagrimeo, hiperemia de la conjuntiva $\mathrm{y}$ fotosensibilidad ${ }^{10,11,27}$.

El principal síntoma oral es la xerostomía o sensación de boca seca por falta o disminución de saliva, la que ocasiona problemas funcionales durante la alimentación, mayor susceptibilidad a las caries, enfermedad periodontal y predisposición a las infecciones orales, especialmente candidiasis ${ }^{10,11,27}$. Los pacientes también pueden acusar sensación de sequedad en otras áreas como nariz, garganta, vagina, recto y piel $^{43}$.

Por otra parte, Ríos et al analizaron la historia clínica de 26 pacientes con diagnóstico de SS juvenil primario (según criterios validados para población adulta), atendidos entre los años 2002 y 2012. En 8 pacientes (30.7\%) la PCRI fue la manifestación inicial y hubo episodios recurrentes en 2 pacientes (7,6\%). Al estudio de anticuerpos, hubo pacientes positivos para factor reumatoide, anti-Ro/SSA, anti-La/SSB, y ANA ${ }^{37}$.

A la fecha, aún no existe un estudio que demuestre la relación entre ambas patologías debido principalmente a su baja frecuencia en la población.

\section{Tratamiento}

Históricamente los tratamientos han evolucionado desde procedimientos invasivos a otros conservadores ${ }^{2}$. Los primeros incluían sección del nervio timpánico, ligadura del conducto parotídeo, inyección de esclerosantes, parotidectomía total o parcial y radioterapia en dosis bajas ${ }^{1,2}$, mientras que los segundos incluyen masajes glandulares, calor local, uso de antibióticos y antiinflamatorios y lavados intraductales ${ }^{35}$. El uso de antibióticos se podría reservar para aquellos casos con evidencias clínicas de infección bacteriana, sim embargo, su uso no altera la duración de los episodios ${ }^{2}$ y contribuirían a la generación de resistencia ${ }^{14}$. El uso de anti inflamatorios sería recomendable exclusivamente para el alivio sintomático ${ }^{12}$.

En 1986, Galili et al reportaron el efecto terapéutico de la sialografía, debido al lavado de las glándulas, sentando la base del tratamiento conservador de la PCRI ${ }^{44}$.

En relación a esto último, Landaeta et al recomiendan la estimulación glandular con calor local, aumento en ingesta de líquidos, consumo de cítricos y goma de mascar. Mediante lavados intraglandulares vía conducto parotídeo, con un medio de contraste yodado, consiguió recuperación del sistema ductal -comprobada con sialografía-, aumento del flujo salival y recurrencias de menor duración en el $80 \%$ de los $\operatorname{casos}^{14,45}$. $\mathrm{Su}$ protocolo sigue vigente, y consiste en un lavado semanal durante 4-5 semanas, luego cada 15 días por 4 sesiones, y posteriormente $1 \mathrm{vez}$ al mes hasta completar un año, momento en que se controla imagenológicamente. En 3 años los pacientes se encuentran con sus glándulas parótidas clínica e imagenológicamente normales, logrando en la mayoría de los casos la remisión antes de la pubertad, o bien recurrencias de máximo 1 día de duración, casi indoloras y sin compromiso del estado general ${ }^{14}$. El mecanismo de acción sería a través de antisepsia o bien arrastre físico ${ }^{45}$ (figuras 4 y 5 ).

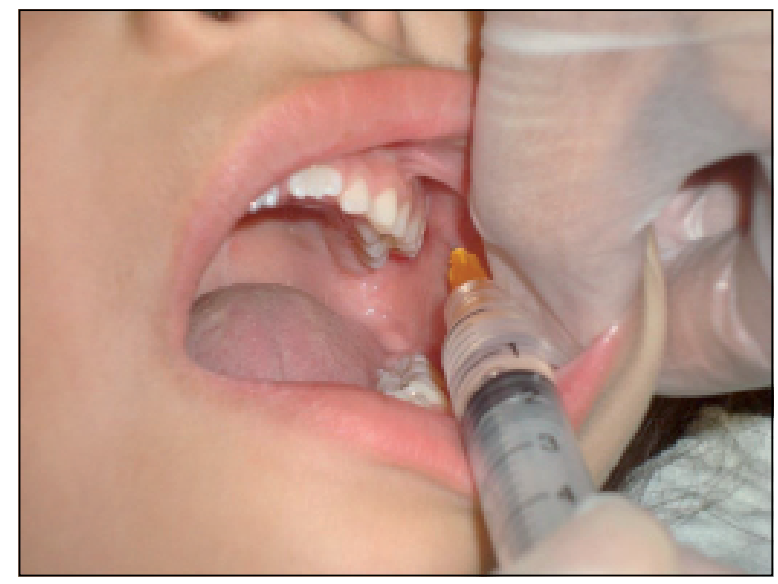

Figura 4. Infiltración em el conducto parotídeo de solución en base a médio de contraste para permitir lavado glandular. 


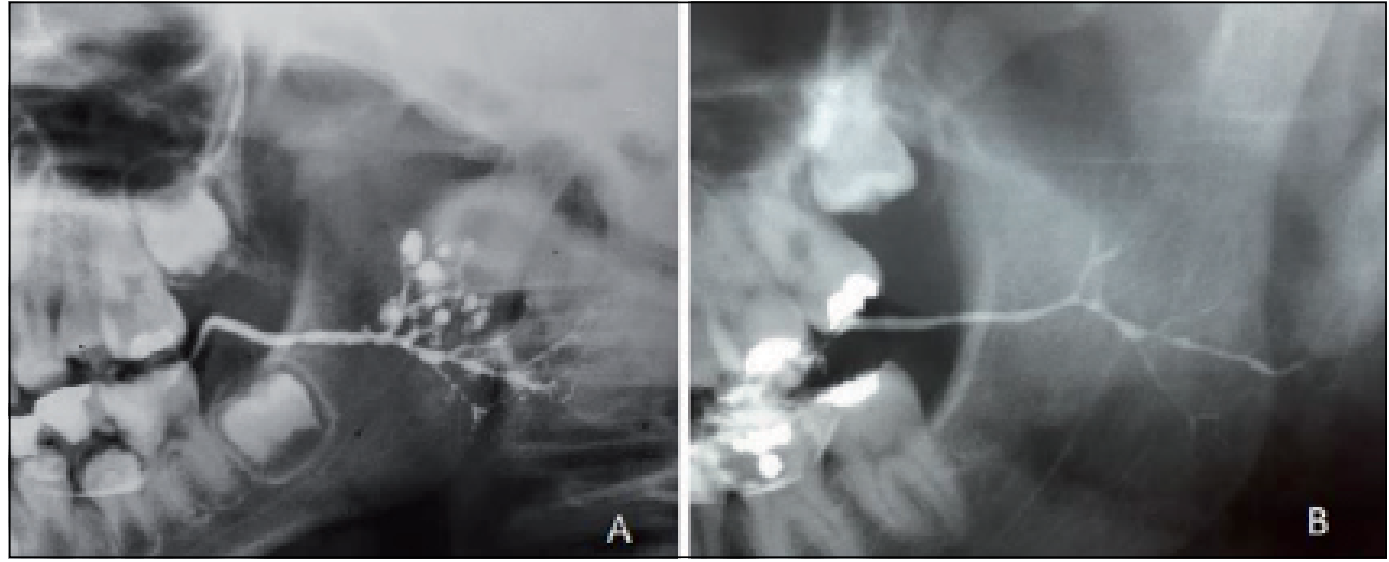

Figura 5. Sialografía de paciente com $\mathrm{PCRI}$ al inicio del tratamento (A) em donde se observa el compromiso del sistema ductal. Sialografía del mismo paciente tras 10 años de realizar lavados intraglandulares en donde se observa anatomia y función conservada de sistema ductal glandular (B).
Rostión et al plantean el uso de mucolíticos (Bromhexina en dosis de $4 \mathrm{mg}$ cada $8 \mathrm{~h}$ ) en pacientes con parotiditis crónica recurrente durante los períodos agudos de la enfermedad, ya que este tipo de solución es capaz de diluir la secreción salival facilitando su excreción disminuyendo el dolor y el aumento de volumen parotídeo ${ }^{35}$.

La respuesta al uso de mucolítico en el grupo con PCRI fue favorable en el $100 \%$ de los casos con disminución progresiva del aumento de volumen y desaparición del dolor en las primeras $48 \mathrm{~h}$ después de iniciado el tratamiento en un $60 \%$ de los casos y dentro de las $96 \mathrm{~h}$ en los pacientes restantes ${ }^{35}$

Otra solución que puede instilarse dentro del conducto es metil violeta al 1\% o violeta de genciana (antiséptico y antihelmíntico). Método simple y con efectos rápidos que ha sido utilizado desde los años 60 . Zou et al, lo utilizó en siete pacientes con parotiditis crónica en que otros tratamientos conservadores no tuvieron los resultados esperados ${ }^{46}$.

En ellos se realizó la inyección del compuesto en la glándula afectada: ninguno presentó recidiva posterior al tratamiento en un seguimiento que fue de los tres meses a los dos años. Wang et al trataron a 16 pacientes con el mismo procedimiento, en el cual a la sialografía posterior se observó la atrofia de la glándula afectada, no mostrando recidiva ${ }^{47}$. Como efectos secundarios, se relata la inflamación de la glándula durante algunas semanas. No obstante, es importante mencionar que estos estudios fueron realizados principalmente en adultos ${ }^{46-48}$. Sin embargo, en un estudio chileno realizado por Arregui et al se relata el caso de una niña de cuatro años que recibió este tratamiento, en la cual no hubo ningún episodio de parotiditis en un seguimiento de cinco meses. Ellos concluyen que en los casos en que la sialografía no genere los resultados esperados, el tratamiento con violeta de genciana sea la siguiente opción terapéutica ${ }^{49}$.
Baurmash et al recomiendan el uso de glucocorticoides, para disminuir la respuesta inflamatoria y restaurar la permeabilidad vascular, disminuyendo el infiltrado de proteínas plasmáticas. A esto deben incluirse lavados intraglandulares cada 3 meses. Por esta última razón, varios estudios no consideran efectivos los glucocorticoides. También recomienda el uso de sialogogos y la estimulación mecánica del flujo salival ${ }^{24}$.

Nahlieli et al aplicaron un lavado de cada glándula con $60 \mathrm{ml}$ de suero además de una inyección vía endoscopio de $100 \mathrm{mg}$ de hidrocortisona, más una indicación de amoxicilina con ácido clavulánico por vía endovenosa. 24 pacientes (92\%) permanecieron libres de síntomas por entre 4 meses y 36 meses $^{1}$.

Capaccio et al usando un protocolo similar, obtuvo que 9 de 14 pacientes no presentaron recurrencia de los episodios, en un promedio de 20 meses $^{2}$.

La revisión sistemática de Ramakrishna et al realizada en el año 2014 concluyó que el tratamiento con sialendoscopia acompañado de antibióticos o bien de glucocorticoides (dependiendo del estudio) resultaba en un $73 \%$ de los pacientes sin episodios posteriores. Sin embargo, el tamaño muestral de los estudios era bajo, y el tiempo de seguimiento variaba entre 0 y 36 meses $^{19}$.

\section{Conclusión}

La PCRI es una patología relevante en la población pediátrica en el ámbito local e internacional por lo que todo profesional de la salud debe conocer sus manifestaciones clínicas. Su diagnóstico se basa principalmente en la historia clínica y examen físico, y se apoya en exámenes imagenológicos, dentro de los que destacan la ecografía y la sialografía.

Importante es realizar el diagnóstico diferencial con muchas otras patologías que cursan con parotido- 
megalia como parotiditis viral, parotiditis bacteriana, linfoma, VIH, y síndrome de Sjögren por mencionar las más importantes. Se han propuestos diversos modelos etiopatogénicos, sin embargo, los más consistentes respecto a la sintomatología, historia clínica y efectividad de los tratamientos sugieren un deterioro en la actividad de esfínter del conducto parotídeo. El control periódico con el odontólogo permite la mantención de una cavidad oral sin focos infecciosos que puedan favorecer la colonización ascendente por un conducto parotídeo con anomalías anatómicas.

El enfoque actual de tratamiento es conservador, y la mejor evidencia disponible apoya el uso de sialendoscopia con irrigación y administración de antibióticos y/o corticoides vía conducto parotídeo, sin embargo, existirían buenos resultados con lavados intraglandulares con soluciones fisiológicas sin necesidad de sialendoscopio. Los pacientes deben ser manejados desde el punto de vista multidisciplinario ya que las terapias indicadas son bastante diversas que van desde tratamientos poco invasivos como masajes, calor local, antibióticos y anti inflamatiorios hasta tratamientos más invasivos como infiltración de soluciones dentro del conducto, biopsias, ligadura del conducto e incluso parotidectomía.

\section{Responsabilidades éticas}

Protección de personas y animales: Los autores declaran que los procedimientos seguidos se conformaron a las normas éticas del comité de experimentación humana responsable y de acuerdo con la Asociación Médica Mundial y la Declaración de Helsinki.

Confidencialidad de los datos: Los autores declaran que han seguido los protocolos de su centro de trabajo sobre la publicación de datos de pacientes.

Derecho a la privacidad y consentimiento informado: Los autores han obtenido el consentimiento informado de los pacientes y/o sujetos referidos en el artículo. Este documento obra en poder del autor de correspondencia.

\section{Conflicto de intereses}

Los autores declaran no tener conflicto de intereses.

\section{Referencias}

1. Nahlieli O, Shacham R, Shlesinger M, Eliav E. Juvenile recurrent parotitis: a new method of diagnosis and treatment. Pediatrics. 2004;114:9-12.

2. Capaccio P, Sigismund PE, Luca N, Marchisio P, Pignataro L. Modern management of juvenile recurrent parotitis. J Laryngol Otol. 2012;126:125460

3. Vinagre C, Martínez MJ, Avendaño LF, Landaeta M, Pinto ME. Virology of infantile chronic recurrent parotitis in Santiago de Chile. J Med Virol. 2003;70:459-62.

4. Gadodia A, Seith A, Sharma R, Thakar A. MRI and MR sialography of juvenile recurrent parotitis. Pediatr Radiol. 2010;40:1405-10.

5. Leerdam CM, Martin HC, Isaacs D. Recurrent parotitis of childhood. J Paediatr Child Health. 2005;41:631-4.

6. Reid E, Douglas F, Crow Y, Hollman A, Gibson J. Autosomal dominant juvenile recurrent parotitis. J Med Genet. 1998;35:417-9.

7. Quenin S, Plouin-Gaudon I, Marchal F, Froehlich P, Disant F, Faure F. Juvenile recurrent parotitis: sialendoscopic approach. Arch Otolaryngol Head Neck Surg. 2008;134:715-9.

8. Sitheeque M, Sivachandran Y, Varathan $\mathrm{V}$, Ariyawardana A, Ranasinghe A.
Juvenile recurrent parotitis: clinical, sialographic and ultrasonographic features. Int J Paediatr Dent. 2007;17:98104.

9. Reddy SS, Namita N, Raghav N, Devaraju D, Shridevi G. Report of a rare case of juvenile recurrent parotitis and review of literature. European Archives of Paediatric Dentistry. 2009;10:31-4.

10. Cohen HA, Gross S, Nussinovitch M, Frydman M, Varsano I. Recurrent parotitis. Arch Dis Child 1992;67:1036-7.

11. Chitre VV, Premchandra DJ. Recurrent parotitis. Arch Dis Child. 1997;77:359-63.

12. Nazar M, Iñiguez O, Der M, et al. Parotitis acute recurrent in the child. Rev Chil Pediatr. 2001;72:437-42.

13. Miziara ID, Campelo VE. Infantile recurrent parotitis: follow up study of five cases and literature review. Braz J Otorhinolaryngol. 2005;71:570-5.

14. Landaeta M, Giglio MS, Ulloa MT, Martínez MJ, Pinto ME. Clinical, microbiological aetiology and therapeutic aspects in infantil chronic recurrent parotitis (PCRI). Rev Chil Pediatr. 2003;74:269-76.

15. Morales-Bozo I, Urzúa-Orellana B, Landaeta $\mathrm{M}$, et al. Molecular alterations of parotid saliva in infantile chronic recurrent parotitis. Pediatr Res. 2007;61:203-8.

16. Shkalim V, Monselise Y, Mosseri R, Finkelstein Y, Garty BZ. Recurrent parotitis in selective IgA deficiency. Pediatr Allergy Immunol. 2004;15:281-3.

17. Mandel L, Bijoor R. Imaging (computed tomography, magnetic resonance imaging, ultrasound, sialography) in a case of recurrent parotitis in children. J Oral Maxillofac Surg. 2006;64:984-8.

18. Chaparro G, Méndez V, Rodríguez R, Rojas-Morales T. Parotiditis Crónica Recurrente o Síndrome de Sjögren Primario Juvenil?: Reporte de un Caso. Rev Chil Pediatr. 2009;80:361-6.

19. Ramakrishna J, Strychowsky J, Gupta $\mathrm{M}$, Sommer DD. Sialendoscopy for the management of juvenile recurrent parotitis: A systematic review and meta analysis. The Laryngoscope. 2015;125:1472-9.

20. Ardekian L, Klein H, Al Abri R, Marchal F. Sialendoscopy for the diagnosis and treatment of juvenile recurrent parotitis. Rev Stomatol Chir Maxillofac Chir Orale. 2014;115:17-21.

21. Mikolajczak S, Meyer MF, Beutner D, Luers JC. Treatment of chronic recurrent juvenile parotitis using sialendoscopy. Acta Otolaryngol. 2014;134:531-5.

22. Canzi P, Occhini A, Pagella F, Marchal F, Benazzo M. Sialendoscopy in juvenile recurrent parotitis: a review of the literature. Acta Otorhinolaryngol Ital. 2013;33:367-73.

23. Schneider H, Koch M, Künzel J, Gillespie MB, Grundtner P, Iro H, Zenk J. Juvenile 
recurrent parotitis: a retrospective comparison of sialendoscopy versus conservative therapy. Laryngoscope. 2014;124:451-5.

24. Baurmash HD. Chronic recurrent parotitis: a closer look at its origin, diagnosis, and management. J Oral Maxillofac Surg. 2004;62:1010-8.

25. Concheiro GA, Bellver CE, Garrido RR García-Tornel FS. Chronic recurrent parotitis in childhood. An Esp Pediatr. 2000;53:418-21.

26. Saarinen R, Kolho KL, Davidkin I, Pitkäranta A. The clinical picture of juvenile parotitis in a prospective setup. Acta Paediatr.2013; 102:177-81.

27. Ericson S, Zetterlund B, Öhman J. Recurrent parotitis and sialectasis in childhood: clinical, radiologic, immunologic, bacteriologic, and histologic study. Annals of Otology, Rhinology \& Laryngology. 1991;100:52735.

28. Schorr B, Mandel L. Diagnosing Juvenile Recurrent Parotitis. Case Reports. The New York state dental journal. 2016;82:36-9.

29. Marsman W, Sukhai R. Recurrent parotitis and isolated IgG3 subclass deficiency. European journal of pediatrics. 1999;158:684.

30. Friis B, Pedersen FK, Schiødt M, Wiik A, Høj L, Andersen V. Immunological studies in two children with recurrent parotitis. Acta Pediátrica. 1983;72:265-8.

31. Bernkopf E, Colleselli P, Broia V, De Benedictis FM. Is recurrent parotitis in childhood still an enigma? A pilot experience. Acta Pediátrica. 2008;
97:478-82.

32. Nahlieli O, Baruchin AM. Endoscopic technique for the diagnosis and treatment of obstructive salivary gland diseases. Journal of oral and maxillofacial surgery. 1999;57:1394-401.

33. Civilibal M, Canpolat N, Yurt A, et al. A child with primary Sjögren syndrome and a review of the literature. Clin Pediatr (Phila). 2007;46:738-42.

34. Seifert G. Aetiological and histological classification of sialadenitis. Pathologica. 1997;89:7-17.

35. Rostión A, Giuliano V, Acosta V. Parotiditis crónica recurrente en el niño. Rev chil pediatr. 2004;75:43-7.

36. Shacham R, Droma EB, London D, et al. Modern management of juvenile recurrent parotitis. J Laryngol Otol. 2012;126:1254-60.

37. Ríos GB, Saldarriaga RL, Tupinamba H, Leitão-de-Azevedo M. Síndrome de Sjögren juvenil primario: Estudio de cohorte. Rev Cub Reumatol. 2015;17:407.

38. Potet J, Arnaud F-X, Valbousquet L, et al. Pneumoparotid, a rare diagnosis to consider when faced with unexplained parotid swelling. Diagnostic and interventional imaging. 2013;94:95-7.

39. Lieder A, Franzen, A. Management of primary malignant lymphoma of the parotid gland in a series of seven hundred and forty-five patients. Clin Otolaryngol. 2017;42:477-480. doi:10.1111/coa.12635

40. Wilson KF, Meier JD, Ward PD. Salivary gland disorders. American family physician. 2014;89:882-8.

41. Seddon B, Padley S, Gazzard B.
Differential diagnosis of parotid masses in HIV positive men: Report of five cases and review. International journal of STD \& AIDS. 1996;7:224-7.

42. Lawn S, Checkley A, Wansbrough-Jones M. Acute bilateral parotitis caused by Mycobacterium scrofulaceum: immune reconstitution disease in a patient with AIDS. Sexually transmitted infections. 2005;81:517.

43. Ladino M, Gasitulli A, Campos X. Síndrome de Sjögren. Caso clínico. Rev chil pediatr. 2015;86:47-51.

44. Galili D, Marmary Y. Juvenile recurrent parotitis: clinicoradiologic followup study and the beneficial effect of sialography. Oral Surg Oral Med Oral Pathol. 1986;61:550-6.

45. Landaeta M, Giglio Maira MS, Molina V, Cobos Segovia L, Espinoza L. Parotiditis crónica recurrente infantil: alternativa de tratamiento. Rev dent Chile. 1992;83:4-7.

46. Zou ZJ, Wang SL, Zhu JR, Wu QG, Yu SF. Chronic obstructive parotitis. Report of ninety-two cases. Oral Surg Oral Med Oral Pathol. 1992 73:434-40.

47. Wang S, Li J, Zhu X, et al. Gland atrophy following retrograde injection of methyl violet as a treatment in chronic obstructive parotitis. Oral Surg Oral Med Oral Pathol Oral Radiol Endod. 1998;85:276-81.

48. Motamed M, Laugharne D, Bradley PJ. Management of chronic parotitis: a review. J Laryngol Otol. 2003;117:521-6.

49. Arregui V, Tamblay N, Esquivel C. Caso clínico: Un tratamiento alternativo a la parotiditis crónica. Rev Otorrinolaringol Cir Cabeza Cuello. 2008;68:43-8. 